\title{
PEDAGOGIAS DA LÍNGUA: MUITO SISO E POUCO RISO
}

\author{
Maria Inês Pagliarini CoX
}

\begin{abstract}
Talvez tivéssemos de deixar de ser professores para poder aprender a formular um pensamento em cujo interior ressoe, desembaraçadamente, o riso.
\end{abstract}

(Larrosa, 1998, p. 210)

RESUMO: Neste ensaio, revisito as noções de "práticas de educação não-formal" e "práticas de educação formal", tomadas em sentido genérico. Rememorados os sentidos comumente atribuídos aos dois termos do binômio "práticas de educação não-formal" e "práticas de educação formal", passo a refletir sobre elas especificamente como fulcros de aprendizagem da língua materna. Participando, direta ou indiretamente, das práticas sociais cotidianas, aprendemos os gêneros discursivos a elas associados. Nelas, aprendemos as fôrmas, mas aprendemos também a potência de diferenciação das línguas vivas que não se deixam imobilizar por sistemas. Contudo, quando a língua materna vira matéria escolar, sua potência de diferenciação vira uma anomalia a ser corrigida, curada. Tem sido assim ao longo de toda a história do ensino formal de língua portuguesa na instituição escolar.

Palavras-chave: Práticas de educação não-formal. Práticas de educação formal. Domínio da língua materna.

\section{LANGUAGE PEDAGOGIES: MUCH SOUNDNESS, LITTLE FUN}

ABSTRACT: In this essay, I revisit the notions of 'informal education practices' and 'formal education practices' taken in their generic sense. After remembering the meanings commonly attributed to

Professora do Programa de Mestrado em Estudos da Linguagem, da Universidade Federal do Mato Grosso (UFMT).E-mail: 1cox@terra.com.br

Disponível em <http://www.cedes.unicamp.br> 
both terms, I reflect upon them specifically as fulcrums of mother tongue learning. Since they are direct or indirect participants in the daily social practices, we learn the discourse genres associated with them. With them, we learn not only the rules of language but also the differentiation potential of living languages, which foil the petrifying power of rules. Nevertheless, when mother tongue becomes a school subject, its differentiation potential becomes an anomaly to be corrected or cured. It has always been so all through the whole history of the formal education of the Portuguese language in school institutions.

Key words: Informal education practices. Formal education practices. Mother tongue mastery.

$P$

ensar a propósito do tema desta publicação - linguagens em práticas de educação formal e não-formal - não me parece ser tarefa facilmente mastigável. $\mathrm{O}$ tema me sugere tantas vias que não sei por qual enveredar - afinal, elas se entrecruzam aqui e ali! Porém, não há fôlego para percorrê-las em conjunto. Assim, sinto-me inclinada a começar dizendo, mais com o auxílio do saber de praça pública e menos pelo recurso a autoridades no assunto, como, no quadro deste ensaio, vou significar as expressões "práticas de educação não-formal" e "práticas de educação formal", sem, contudo, conseguir antever os próximos passos. Temo que me levem a um labirinto e me façam dar voltas e mais voltas sem encontrar a saída.

Pela locução nominal "práticas de educação", designo todas as práticas sociais cotidianas que, do nascimento à morte das pessoas, sem conhecer descanso, constituem instâncias do ensinar e do aprender os saberes de que todas as sociedades necessitam para prosseguir na reinvenção ordinária da vida de seus grupos e seus sujeitos. Aprender e ensinar são experiências ubíquas na vida dos homens em sociedade. A educação confunde-se com a vida concreta e cotidiana dos grupos humanos. Aprender não é uma questão de opção - estamos condenados a aprender, queiramos ou não. Bem arrematam este exercício de "sensocomunologia" as palavras singelas ditas por Carlos Rodrigues Brandão na abertura do livro $O$ que é educação:

Ninguém escapa da educação. Em casa, na rua, na igreja ou na escola, de um modo ou de muitos, todos nós envolvemos pedaços da vida com ela: para aprender, para ensinar, para aprender-e-ensinar. Para saber, para fazer, para ser 
ou para conviver, todos os dias misturamos a vida com a educação. Com uma ou com várias: educação? Educaçôes. (Brandão, 1981, p. 7)

Sinto-me inclinada ainda a ver as práticas de educação como práticas de troca, práticas interacionais. Onde há agrupamentos humanos, há encontros. Onde há encontros, há interação, com ou sem palavras. Onde há interação, há aprendizagem. Interagir e aprender são, pois, ações inalienáveis.

Prosseguindo na lida com o tema desta publicação, vejo-me agora envolvida no exercício de explicar a que vou me referir ao juntar, como determinante, os adjetivos "não-formal" e "formal" ao substantivo "educação".

Quando uso a locução "práticas de educação não-formal”, penso que, onde há homens interagindo, há homens, consciente ou inconscientemente, transmitindo e reinventando saberes. Assim, práticas de educação não-formal são todas as práticas cotidianas. Onde há gente vivendo, há gente ensinando e aprendendo. Práticas de educação não-formal misturam-se com a vida - enquanto trabalham, se divertem, brigam, amam e convivem, os homens se educam de mil maneiras que nada ou muito pouco lembram das técnicas pedagógicas escolares. Há quem designe tais formas comunitárias patentes ou latentes de ensinar-aprender pelo termo "socialização". Como se pode ler numa formulação de Brandão (1981, p. 32), com sabor de trocadilho, viver o fazer faz o saber. Ainda, segundo o autor:

Os que sabem: fazem, ensinam, vigiam, incentivam, demonstram, corrigem, punem e premiam. Os que não sabem espiam, na vida que há no cotidiano, o saber que ali existe, vêem fazer e imitam, são instruídos com o exemplo, incentivados, treinados, corrigidos, punidos, premiados e, enfim, aos poucos aceitos entre os que sabem fazer e ensinam com o próprio exercício vivo do fazer. Esparramadas pelos cantos do cotidiano, todas as situações entre pessoas e a natureza - situaçôes sempre mediadas pelas regras, símbolos e valores da cultura do grupo - têm em menor ou maior escala a sua dimensão pedagógica. Aí todos os que convivem aprendem, aprendem da sabedoria do grupo social e da força da norma dos costumes da tribo, o saber que torna todos e cada um pessoalmente aptos e socialmente reconhecidos e legitimados para a convivência social, o trabalho, as artes da guerra e os ofícios do amor. (Brandão, 1981, p. 20 e 21)

Evidentemente a inspiração de Brandão ao assim dizer da educação não-formal se enraíza na sua lata e densa sabedoria acerca das 
sociedades tradicionais, sociedades estáveis que seguem se reproduzindo com poucos abalos sísmicos à identidade grupal. Porém, tão apropriado quanto pensar que educação e vida se confundem em tais sociedades, é pensar que educação e vida se confundem nas sociedades complexas da alta modernidade. Nelas, tudo se renova e inova tão vertiginosamente que a empresa de aprender não cessa nunca.

O que é mais próprio das práticas de educação não-formal é seu caráter difuso. Ela é feita por todos os que convivem e interagem e não apenas por professores, e ocorre em todos os contextos e as situações sociais e não apenas na sala de aula. E como é realizada por diferentes atores em diferentes contextos, não raro, abriga o conflitual, o contraditório. À guisa de ilustração, recorro aqui ao descompasso que, freqüentes vezes, instala-se entre as palavras de ordem que circulam em ações, gestos e voz dos pais no espaço da casa e as palavras de ordem que circulam em açôes, gestos e voz dos amigos no espaço da rua. Enfim, práticas de educação não-formal ensinam o claro-escuro, o alto-baixo, o siso-riso, os regulamentos-desregulagens de uma formação social num momento histórico dado.

Em sociedades complexas como a nossa, cada vez mais as práticas de educação não-formal deslocam-se da interação face a face para a interação mediada eletronicamente. A televisão e a internet são os principais agentes de socialização no interior de muitos grupos sociais.

Já quando uso a locução "práticas de educação formal”, penso em escolarização, em espaços-tempos de ensinar-aprender instituídos à margem da cadência da vida cotidiana. Penso em especialistas produzindo ciência, teoria, sem nunca terem sido homens de arte. Penso ainda em outros especialistas transformando ciência em matérias curriculares, disciplinas escolares. Penso em pedagogia, métodos de ensino. Penso em atores sociais, transformados em professores-alunos, encontrando-se ordinariamente em espaços especializados para a agência da educação (é bem verdade que hoje essa imagem do agrupamento na sala de aula contrasta com a do aluno sozinho, olhos fixos na tela de um monitor e dedo no mouse). Práticas de educação formal envolvem seriaçōes e burocracias (matrículas, provas, exames, diplomações etc.), começam e terminam. Melhor dizendo, terminavam, já que nas sociedades contemporâneas, onde tecnologias, saberes e valores caducam da noite para o dia, a educação permanente ganha cada vez mais espaço. 
A educação formal expia-se do escuro, do baixo, do riso, das desregulagens, projetando a imagem de uma sociedade ideal.

Rememorados os sentidos comumente atribuídos aos dois termos do binômio "práticas de educação não-formal" e "práticas de educação formal", vejo-me agora pensando nelas especificamente como fulcros de aprendizagem da língua materna. O termo "língua materna" cobre o conjunto aberto de usos e formas lingüísticas que aprendemos com a mãe. A mãe é aqui uma metáfora do que está próximo - família, grupo de companheiros, vizinhos, meios de comunicação de massa, cujas vozes não podemos não escutar vivendo umbilicalmente ligados à TV, à casa, ao quintal, à pracinha, à rua, ao bairro. As instâncias, por excelência, de aquisição de usos e formas da língua materna são, pois, as práticas sociais do cotidiano. Afinal, assinala Bakhtin (1953/1992, p. 279), todas as práticas sociais envolvem a utilização da língua. Se múltiplas são as esferas de atividade humana, múltiplos são os usos da língua.

Os usos da língua efetuam-se por intermédio de textos concretos que têm por referência gêneros do discurso, definidos como tipos relativamente estáveis de enunciados (Bakhtin, 1992, p. 279) correspondentes a uma mesma esfera de práticas sociais e, portanto, a uma mesma esfera de utilização da língua. Como as esferas de atividade humana de uma sociedade se transformam no tempo e no espaço, também os gêneros de discurso:

A riqueza e a variedade dos gêneros do discurso são infinitas, pois a variedade virtual da atividade humana é inesgotável, e cada esfera dessa atividade comporta um repertório de gêneros do discurso que vai diferenciando-se e ampliando-se à medida que a própria esfera se desenvolve e fica mais complexa. (Bakhtin, 1992, p. 279)

Participando, direta ou indiretamente, das práticas sociais cotidianas, aprendemos os gêneros a elas associados. Pelos nossos ouvidos, entram o melífluo do "manhês", o lúdico dos jogos e das brincadeiras, o cerimonioso e contido da distância pública, o agônico dos embates e das pelejas, o ordinário das palavras misturadas aos fazeres corriqueiros e gêneros outros inerentes a atividades humanas que florescem em esferas mais simples da vida social, tecidas principalmente por uma cultura bastante oral. Então, começam a sonhar por e para nós o ingresso em esferas sociais mais complexas - profissionais, burocráticas, políti- 
cas, científicas, acadêmicas, literárias, artísticas, jornalísticas e outras mais - que engendram gêneros discursivos tributários de uma cultura escrita. Bakhtin (1992, p. 281) nomeia como "gêneros primários" aqueles associados a esferas sociais mais simples e a formas de comunicação verbal espontâneas e como "gêneros secundários" aqueles associados a esferas sociais mais complexas e a formas de comunicação verbal planejadas e dependentes de uma cultura letrada.

A noção de gênero do discurso ancora-se no tripé tema-composição-estilo. "Tema" é tudo aquilo que se pode dizer num discurso, os sentidos que constrói e põe em circulação; "composição" é a arquitetura, o formato, a estrutura organizacional dos textos como um todo; "estilo”, a forma resultante da seleção dos recursos lingüísticos (fonológicos, morfológicos, lexicais, sintáticos etc.). Estes três elementos se fundem indissoluvelmente no todo do enunciado, e todos eles são marcados pela especificidade de uma esfera de comunicação (Bakhtin, 1992, p. 279).

Ao revisitarem Bakhtin, muitos leitores contemporâneos têm se fixado no caráter estável dos enunciados concretos, ou seja, dos textos em correlação com os gêneros do discurso. Gostaria de lembrar aqui que o autor modaliza o predicado "estável", dizendo que os enunciados são "relativamente estáveis". E essa modalização não é algo que se possa subestimar, algo insignificante. Nela ecoam formulações feitas anteriormente em Marxismo e filosofia da linguagem (1929/1979), na sua crítica contundente ao postulado saussureano de que a língua é um sistema estável, abstrato, homogêneo, unívoco, acabado, fechado em si mesmo. Tal concepção é, para ele, um artifício teórico, fruto de abstração científica e monografias acadêmicas. Ela não dá conta do real da língua que se apresenta instável, dinâmica, histórica, plurívoca, inacabada, aberta ao mundo da vida. A visão da língua como um sistema abstrato estaria ligada à herança filológica da qual o pensamento lingüístico ocidental não consegue se desvencilhar. Quer dizer, o estudo das línguas vivas estaria glosando os procedimentos práticos e teóricos aplicados ao estudo das línguas mortas conservadas em documentos escritos. O pensamento filológico nasce e nutre-se dos cadáveres das línguas escritas no que é imitado pelo pensamento lingüístico. Nos termos do próprio autor:

Os imperativos da filologia engendraram a lingüística, acalentaram-na e deixaram dentro de suas fraldas a flauta da filologia. Essa flauta tem por fun- 
ção despertar os mortos. Mas essa flauta carece da potência necessária para dominar a fala viva, com sua evolução permanente. (...). Em toda parte a lingüística é filha da filologia. Submetida aos imperativos desta, a lingüística (...). elaborou seus métodos e categorias trabalhando com monólogos mortos, ou melhor, com um corpus de enunciações desse tipo (inscriçóes em monumentos antigos), cujo único ponto em comum é o uso da mesma língua. (Bakhtin, 1979, p. 82 e 83)

Destarte, ao acentuar o caráter "relativo" da estabilidade dos gêneros, Bakhtin reafirma sua disposição para compreendê-los no fluxo da comunicação verbal, tal como se apresentam na vida corrente. Nos seus usos, as línguas revelam-se rebeldes às fronteiras de sistemas de formas idênticas; constituem processos ininterruptos de diferenciação e mudança; são inerentemente polilíngües. Nos seus usos, as muitas línguas de uma mesma língua nunca são encontradas em estado puro; elas tanto se sobrepóem, se mesclam, se contaminam mutuamente, quanto se contrastam, se separam e se redefinem continuamente na/ pela ação verbal dos falantes (Signorini, 2002, p. 119). Devir e diferença e não estado e identidade, eis o que caracteriza uma língua sendo falada. A fim de dar corpo a esse pensamento que a todo momento tende a derivar, recorro a um caso exemplar.

Um dia desses, num final de tarde, como de costume, fui a um supermercado que fica perto de minha casa para comprar pão. Nas estantes próximas ao balcão da padaria, deparei-me com um novo tipo de pão integral, embalado em saco plástico. $\mathrm{Na}$ minha eterna briga com a balança, pus-me a ler as "informaçôes nutricionais". Não encontrei as informaçóes sobre calorias que buscava. Contudo, um detalhe lingüístico chamou-me a atenção. $\mathrm{Na}$ etiqueta adesiva que fechava o saco, além do peso e do preço do produto, podia-se ler o seguinte:

Informaçôes Nutricionais

Consumir em 5 dias - conservar a 25 graus

Ingred.: farinha integral, farinha de trigo comum, gruten e sal. Contém estabilizante, estearoil-2-lactil, lactato de cálcio e conservantes. 
Os olhos e os ouvidos da lingüista excitaram-se diante da palavra "gruten". De repente, em meio a um jargão técnico estéril de voz, um acento sertanejo timbrava um dos termos. A voz insinuava-se no texto, deixando um rastro no papel - o efeito ou metonímia do corpo (Certeau, 1994, p. 249). Refiro-me aqui à troca do "l" pelo "r", fenômeno conhecido como rotacismo, que perpassa toda a história da língua portuguesa tanto em sentido vertical quanto horizontal. ${ }^{1}$ Nos seus quinhentos anos de vida no Brasil, o rotacismo tornou-se um traço altamente estigmatizado, a marca registrada do dialeto caipira, língua que sai da boca de jecas-tatus.

O riso foi a primeira reação, provocado certamente pela emergência extemporânea de um traço de uma língua menor, suja de terra, num texto asséptico que aciona o repertório de gêneros discursivos citadinos e ligados a esferas de atividades de produção, comércio e consumo de alimentos, próprias das sociedades complexas e industrializadas da alta modernidade. Textos desse gênero normalmente veiculam, colados às embalagens, informaçôes acerca dos componentes nutricionais, da validade e das formas de conservação dos produtos (tema). Apresentam uma estrutura composicional rígida, o formato de um elenco de frases e locuções nominais designativas dos ingredientes e são extremamente sintéticos, uma vez que devem ajustar-se aos limites de um rótulo ou de uma etiqueta de balança (composição). Caracterizamse pelo uso de um jargão técnico e de uma linguagem impessoal, formal, escrita, padrão, seca (estilo).

Via-me lendo um texto sério, sisudo, sem graça, produzido por um enunciador que, certamente mero escriba-digitador, copiara os enunciados produzidos num outro tempo e lugar por um enunciador-autor, instituído e legitimado pelo domínio de um saber especializado, mas ainda assim ria. Fazia-me rir o fiapo de voz do jeca-tatu que fluía das profundezas da alma sertaneja e usurpava o lugar a ser ocupado pelo nobre grafema "l", cadáver ressuscitado pelos legitimistas que gramatizaram as palavras da língua portuguesa então nascente, decalcando-as sob a etimologia latina. Era como se estivesse diante da figura do bobo da corte. Desafinando no uso do estilo elevado, a voz desse como que bobo da corte corrói o convencionalismo, os hábitos e os lugares comuns da linguagem. Essa ironia impensada, inusitada, essa ironia do destino, fez-me irromper em riso. O riso explodiu no momento em que a forma "gruten" me fez acordar para a 
esclerose da língua em muitas esferas da vida social. O riso, diz Bergson (1983), castiga a rigidez dos movimentos mecânicos e automáticos, convertendo-a em maleabilidade. $\mathrm{O}$ riso entra em contato com o sério, dialoga com o sério, com essa linguagem elevada que pretende envolver o mundo e compreendê-lo e dominá-lo, com essa linguagem canonizada e aceita que não duvida de si mesma.

O riso desmascara essa linguagem, retira-a de seu lugar, de seus esconderijos, a expõe ao olhar como ela é, como uma casca vazia. (...) E, assim, o riso põe a nu (...) a arbitrariedade e a contingência de qualquer forma estabilizada, (...) impede que as máscaras, crentes de si mesmas, se solidifiquem e se ressequem. E essa é sua contribuição para a aprendizagem: não a destruição das máscaras, mas o reconhecimento de seu caráter de máscaras e o impedimento de que se grudem completamente. (...) E, então, o baile de máscaras converte-se em uma alegre dança. (Larrosa, 1998, p. 223-226)

$\mathrm{Na}$ vida sendo vivida, as múltiplas línguas de nossa língua materna não existem em estado puro, não existem em sistemas fechados. Elas se esquecem de suas leis, normas, regulamentos, transbordam fronteiras, vazam umas nas outras, contaminam-se. Enformam-se e deformam-se sem cessar. São festas, carnavais. As muitas línguas enredam-se numa dança sem fim. E o que delas aprendemos vivendo, por meio de práticas de educação não-formal, traz junto a fluidez da música, das vozes que as impedem de parar de dançar. Aprendemos as fôrmas, mas aprendemos também a potência de diferenciação das línguas vivas que não se deixam imobilizar por sistemas. Aprendemos o esgarçamento das fronteiras, a mistura de códigos. Quando a língua materna vira matéria escolar, sua potência de diferenciação vira uma anomalia a ser corrigida, curada. Tem sido assim ao longo de toda a história do ensino formal de língua portuguesa na instituição escolar.

Num primeiro momento, a escola, amparando-se na tradição filológico-gramatical que, como Bakhtin assinala, erige-se sobre o estudo de cadáveres das línguas mortas, ignora completamente o polilingüismo da vida cotidiana e rejeita todo o saber lingüístico mundano de seus alunos. A escola incumbe-se da missão de suplantar o anômalo e indesejável polilingüismo, pelo monolingüismo da norma-padrão. A norma-padrão, prescrita pelos gramáticos e transformada em matéria 
curricular pela escola, não é a norma culta atestada nos usos formais do português, mas um códice normativo construído, segundo inúmeros estudos, em bases anacrônicas e artificiais:

A codificação que se fez aqui, na segunda metade do século XIX, não tomou a norma culta brasileira de então como referência. Bem ao contrário: a elite letrada conservadora se empenhou em fixar como nosso padrão um certo modelo lusitano de escrita, praticado por alguns escritores do Romantismo. O modelo não foi, portanto, "a" língua de Portugal, como muitos pensam, imaginando uma homogeneidade que, de fato, não existe, já que o português de lá é, como qualquer língua, um emaranhado de variedades. (Faraco, 2002, p. 42 e 43)

Fazendo desse padrão a matéria curricular do ensino de português, a escola passa a cultivar uma atitude purista e a realizar um ensino normativo que vê erro e heresia lingüística em toda parte. Nos termos desse modelo, a forma "gruten", que aparece no texto transcrito anteriormente, faria corar gramáticos de plantão e renderia muita saliva ou tinta na condenação do que se lhes afigura como a derrocada da língua portuguesa na boca da gente ignorante. Além de renegar o polilingüismo da vida cotidiana, esse paradigma se concentra apenas no aspecto gramatical da língua, na contramão do que ocorre na educação informal, que ensina os usos e, ensinando os usos, automaticamente ensina as formas gramaticais. Nele, a matéria curricular não são os gêneros discursivos formais de uma cultura letrada, mas as prescrições gramaticais de uma língua escrita já em desuso, ou seja, morta.

Esse modelo reinou soberano até os anos 60 do século passado. A ruptura prometida pela lingüística estruturalista do início do século não chegou a abalar as bases normativas do ensino de línguas. Aliás, este foi ajudado por ela. A lingüística entra em cena, anunciando a reescrita da história da concepção de língua numa visada descritiva. Esse tratamento descritivo, buscando apreender dos dados lingüísticos a norma objetiva que efetivamente preside os usos de uma língua (e não a norma-padrão), tem o poder de desvelar a natureza regular, sistemática, estrutural, de tudo aquilo que há milênios vinha sendo condenado como erro, como destruição e desordem da gramática. Contudo, para desembaraçar os sistemas dos usos, os lingüistas formais escamoteiam a empresa de definir lingüisticamente uma língua em toda sua natureza proteiforme. Ocupam-se em dela abstrair a 
língua. Acompanhando Saussure (1975), usam a navalha do método. Dicotomizam a linguagem em duas dimensões: língua (langue) e fala (parole). A partir de então, a lingüística passa a ser definida como a ciência da língua, um objeto definido e homogêneo no conjunto indefinido e heterogêneo dos fatos de linguagem (a fala), afinal cumpria escolher entre dois caminhos que não podiam ser trilhados simultaneamente. A fala vira a lixeira da lingüística, abrigando a infinda variação em que resulta uma língua ao ser usada pelos seus falantes. Assim, a lingüística da língua, com sua concepção de sistema homogêneo e regras categóricas, não chega a representar uma ameaça ao monolingüismo da norma-padrão.

Esse modelo de ensino não morreu, mas não reina mais sozinho. Divide, numa antagonia declarada, o espaço do ensino de língua materna com outro modelo quem vem se construindo com base em saberes lingüísticos produzidos pela sociolingüística e pela análise do discurso. No começo da década de 1960, Labov ergue os alicerces da sociolingüística, questionando o princípio da homogeneidade e da invariância do sistema; afasta-se da concepção de língua como sistema monolítico, postulando que a heterogeneidade é inerente a uma comunidade de fala. Se para a lingüística formal a língua é um sistema de invariantes, para a sociolingüística é um sistema de variantes. Uma língua é sempre um mosaico, um compósito de normas que se correlacionam probabilisticamente a fatores sociais, a contextos extralingüísticos. A língua não é mais um UM central, mas a justaposição de vários UNS setorizados. Se a sociolingüística captura o polilingüismo de uma mesma língua, trata-se ainda de um polilingüismo bem-comportado que situa as variaçōes do sistema dentro de fronteiras bem definidas. As misturas de códigos são vistas como fenômenos periféricos, atípicos, no conjunto dos usos "normais" da língua. No novo modelo de ensino de línguas, as premissas da sociolingüística resultam num currículo que, em tese, acolhe a diversidade de normas e opera não com o princípio da correção, mas de adequação lingüística. Se para o primeiro modelo o ideal é o monolingüismo da norma-padrão em qualquer contexto, para o segundo o ideal é um monolingüismo relativista em que norma e contexto entrem em sintonia. $\mathrm{O}$ uso da norma culta passa a ser uma exigência do contexto (o exemplo memorável de adequação ao contexto é a gasta metáfora: ir à praia de terno e gravata é tão inadequado quanto ir à missa de biquíni) e não mais uma exigência incondicional. 
Aos saberes advindos da sociolingüística, são acrescentados aqueles produzidos pela análise de discurso, que se fundou não questionando a homogeneidade do sistema, mas a exclusão do discurso do objeto da lingüística. Apropriando-se dos saberes produzidos no campo da análise de discurso, o currículo escolar incorpora os gêneros textuais, já que a unidade da língua em uso não são, como nos faz crer a lingüística da língua, fonemas, morfemas, palavras, orações ou períodos, mas textos. Textos, por sua vez, são produzidos no universo de gêneros do discurso e é em relação a eles que as normas lingüísticas devem passar a ser pensadas e não mais no vazio. No quadro dessa proposta de ensino, a forma "gruten" seria vista como inadequada ao estilo comum a textos pertencentes àquele gênero que supõe um enunciador sem acentos dialetais forasteiros, mas seria considerada normal numa conversa de bar, por exemplo. Contudo, a vida da língua que, teimosa, esgarça e anarquiza as fronteiras dos gêneros e das normas, e a faz multiplicar-se, é convidada a se retirar da cena da escola. Escolarizados, os gêneros tendem a ser disciplinarizados, transformados em dispositivos destinados a produzir exemplares padronizados. Os gêneros e as normas têm suas fronteiras monitoradas, administradas por uma cultura escolar que ainda não conseguiu desvencilhar-se da lógica da padronização e da identidade. O currículo que absorve o discurso da diversidade, mas coloniza-o por meio de uma racionalidade funcionalista, dispondo cada coisa no seu devido lugar, não é, de modo algum, um currículo que se abre para a multiplicidade. Abrir-se para a multiplicidade significa:

Fazer proliferar o sinal de multiplicação. A diversidade é estática, é estado, é estéril. A multiplicidade é ativa, é um fluxo, é produtiva. A multiplicidade é uma máquina de produzir diferenças - diferenças que são irredutíveis à identidade. A diversidade limita-se ao existente. A multiplicidade estende e multiplica, prolifera, dissemina. A diversidade é um dado - da natureza ou da cultura. A multiplicidade é um movimento. A diversidade reafirma o idêntico. A multiplicidade estimula a diferença que se recusa a se fundir com o idêntico. (Corazza $\&$ Tadeu, 2003, p. 12)

Se na vida os gêneros e as normas lingüísticas dançam, flutuam, na escola são imobilizados, engessados. Para celebrar os prazeres - e até mesmo os perigos - da confusão de fronteiras (Idem, p. 13) 
entre as línguas, nós professores precisamos de aprender a rir da sisudez e austeridade pedagógica:

O riso destrói as certezas. (...) Mas só na perda da certeza, no permanente questionamento da certeza, na distância irônica da certeza, está a possibilidade do devir. O riso permite que o espírito alce vôo sobre si mesmo. $\mathrm{O}$ chapéu de guizos tem asas.

E não venham vocês me dizer que o riso pode ser perigoso. O riso é, certamente, ambíguo e perigoso. Como os livros, como as viagens, como os jogos, como o vinho, como o amor. (...) o riso pode ser benéfico ou maléfico, divino ou satânico. Mas sua ambigüidade não é diferente da ambigüidade radical de qualquer experiência de formação, pelo menos quando a formação não é concebida de uma forma por demais harmoniosa, por demais construtiva, por demais linear, por demais edificante. Na formação existe, às vezes, tensão, destruição, negação. (Larrosa, 1998, p. 227)

Recebido em agosto de 2003 e aprovado em abril de 2004.

\section{Nota}

1. Um estudo do rotacismo na língua portuguesa, sob várias perspectivas, pode ser encontrado em Cox (2001).

\section{Referências bilbiográficas}

BAKHTIN, M. Estética da criação verbal. São Paulo: Martins Fontes, 1992. (original 1953)

BAKHTIN, M.; (VOLOCHINOV, V.N.). Marxismo e filosofia da linguagem. São Paulo: Hucitec, 1979. (original 1929)

BERGSON, H. O riso: ensaio sobre a significação do cômico. Rio de Janeiro: Zahar, 1983.

BRANDÃO, C.R. O que é educação. São Paulo: Brasiliense, 1981.

CERTEAU, M. de. A invenção do cotidiano: artes do fazer. Petrópolis: Vozes, 1994.

CORAZZA, S.; TADEU, T. Composiçôes. Belo Horizonte: Autêntica, 2003. 
Pedagogias da língua: muito siso e pouco riso

COX, M.I.P. Crique aqui: um signo mestiço. Signum: Estudos da Linguagem, Londrina, n. 4, p. 81-94, 2001.

FARACO, C.A. Norma-padrão brasileira: desembaraçando alguns nós. In: Bagno, M. (Org.). Lingüística da norma. São Paulo: Loyola, 2002. p. 37-61.

LARROSA, J. Pedagogia profana: danças, piruetas e mascardas. Porto Alegre: Contrabando, 1998.

SAUSSURE, F. Curso de lingüistica geral. São Paulo: Cultrix, 1975.

SIGNORINI, I. Por uma teoria da desregulamentação lingüística. In: Bagno, M. (Org.). Lingüistica da norma. São Paulo: Loyola, 2002. p. 93-125. 